ceiving $2.0 \mathrm{~g}$ of benorylate three times a day, which observations were the subject of my previous letter (14 April, p. 118).

Further measurements of plasma salicylate levels have been undertaken in the same nine patients and 12 randomly selected patients with active rheumatoid disease of the classic form. All patients were allocated seven days' treatment on benorylate $4.0 \mathrm{~g}(10 \mathrm{ml})$ twice daily followed by a further seven days during which soluble aspirin $1.2 \mathrm{~g}$ four times a day was substituted for benorylate. Venous blood was drawn at 8 a.m. and at four-hour intervals thereafter until 8 p.m. Total and free salicylate concentrations were measured in the separated plasma. Free, unbound, salicylate was separated by membrane ultrafiltration utilizing Centriflo ultrafilters. ${ }^{1}$

The mean total and free salicylate concentrations in the plasma of the nine patients who developed salicylism with benorylate are shown in the accompanying figure, which records the measurements

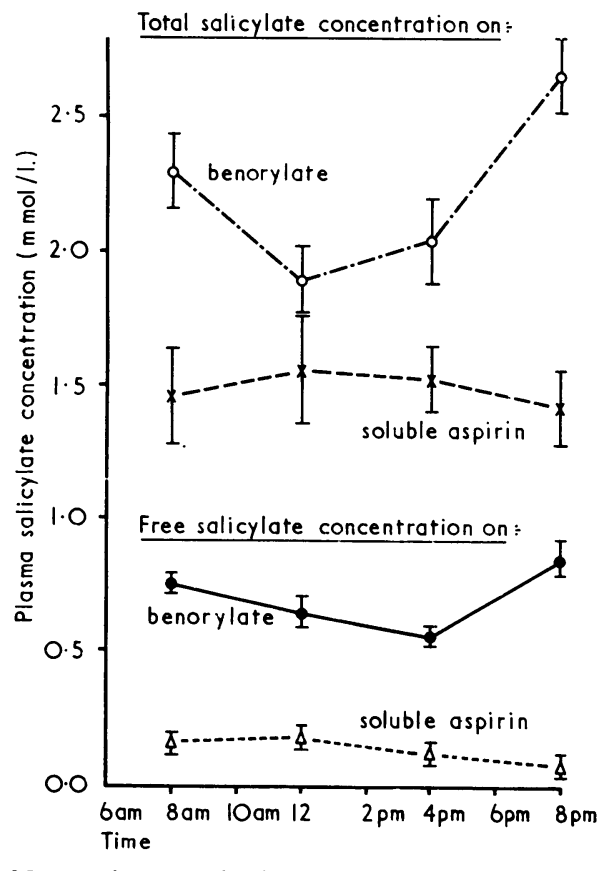

Mean plasma salicylate levels $( \pm$ S.E.M.) at 4-hourly intervals, achieved with benorylate $4 \mathrm{~g}$ twice daily with soluble aspirin $1.2 \mathrm{~g}$ four times
day in nine patients with rheumatoid arthritis.

obtained on the third day of each regimen. In these patients plasma total salicylate concentrations were greater while they were taking benorylate than when taking soluble aspirin, the differences being statistically significant at 8 a.m. $(P=0.02)$ and 8 p.m. $(P<0.01)$. Free salicylate concentrations followed the same pattern except that the levels following benorylate were highly significantly greater than during aspirin administration at each sampling time $(P<0.001)$. When taking aspirin the relationship between plasma free and total salicylate concentrations was in keeping with data obtained in other studies. ${ }^{2}$ However, during benorylate administration the concentration of free salicylate recorded was markedly greater than would be expected at the total plasma salicylate concentrations which were observed. Since toxicity rather than clinical effectiveness is associated with free salicylate concentra- tions greater than $0.6 \mathrm{mmol} / 1$. in most individuals, ${ }^{3}$ then it would seem that the increased incidence of salicylism in these nine patients, when on benorylate, as compared with aspirin treatment, is a reflection of the unexpectedly greater concentrations of unbound salicylate in their plasma during benorylate administration.

Considering the 12 other patients included in the study, the incidence of salicylism was the same on both treatment regimens, one patient developing the symptoms while receiving aspirin and one while taking benorylate. There were no significant differences between the plasma salicylate levels achieved when receiving benoryiate and those obtained while taking aspirin, the mean values being $1.64 \mathrm{mmol} / 1$. at 8 a.m. and $1.68 \mathrm{mmol} / 1$ at 8 p.m. while taking aspirin, and $1.72 \mathrm{mmol} / 1$. at 8 a.m. and $1.78 \mathrm{mmol} / 1$. at 8 p.m. when taking benorylate. These plasma levels are similar to those achieved by Robertson et al. ${ }^{4}$ when giving benorylate to normal volunteers.

Comparison of the two groups of patients reveaied no significant differences in age, sex ratio, duration and severity of the disease process, or previous drug histories. Furthermore, there was no consistent quantitative differences between the plasma concentrations of albumin, alpha- and betaglobulins or IgM, IgA, and IgG. However, an in vitro study of the binding characteristics of the plasma of patients in the study indicated a difference between the two groups in that in the plasma of the patients who developed salicylism on benorylate the ratio of proteinbound to free salicylate was modified by the presence of benorylate at a concentration of $10 \mu \mathrm{g} / \mathrm{ml}$. This modification manifested as a greater concentration of free sa'icylate at each total salicylate concentration than was obtained in the absence of the benorylate molecule. This phenomenon was not observed in plasma from those patients who showed tolerance of benorylate at the recommended dosages.

These results suggest that in certain individuals the benorylate molecule might interfere with the binding of salicylate to plasma proteins, but they do not explain the higher total salicylate concentrations which were observed while the patients were taking benorylate.-I am, etc.,

Research Division,

Merthyr General Hospital,

1 Blatt, W. F., Robinson, S. M., and Bixler, H. J., Analytical Biochemistry, 1968, 26, 151

C., and Smith, P. K., Fournal of Pharmacology

3 Smith, M. J. H., and Dawkins, P. D., fournal of Pharmacy and Pharmacology, 1971, 23, 729.
Robertson, A., Glynn, J. P., and Watson, A. K Xenobiotica, 1972, 2, 339.

\section{Fenfluramine and Growth}

Hormone Release

SIR,-Dr. D. L. F. Dunleavy and others $(7$ July, p. 48) describes increased nocturnal growth hormone secretion in a patient while on fenfluramine. An intermittent sampling method has the advantage of studying growth hormone secretion under conditions as near as possible to those un- der which fenfluramine is commonly used. Their findings might therefore have more clinical relevance than those of Mr. W. R. Sulaiman and Dr. R. H. Johnson (12 May, p. 329).

We, too, have studied overnight growth hormone secretion in a patient before and during treatment with fenfluramine, but by a continuous sampling method, estimating growth hormone in hourly coilections. The pat:ent was a 14-year-old girl weighing 95 $\mathrm{kg}$. Overnight growth hormone secretion was studied on admission to hospital. She was then started on treatment with fenfluramine $40 \mathrm{mg}$ twice daily and a further overnight study was carried out 48 hours later. Before and during the studies she was not dieting and lost no weight. Plasma fenfluramine levels during the second night of study were $144.2 \mathrm{ng} / \mathrm{ml}$ at 21.30 hours and $97 \cdot 2 \mathrm{ng} / \mathrm{ml}$ at 06.00 hours. Growth hormone secretion for the two nights is shown in the figure. The result is inconclusive, but

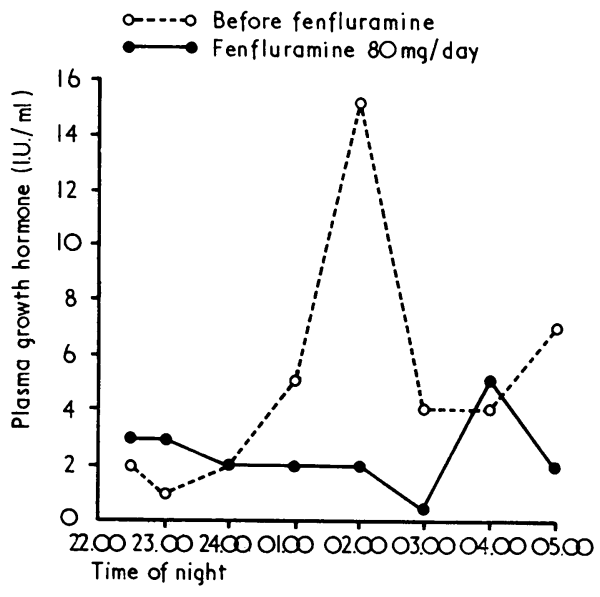

certainly does not suggest increased growth hormone secretion when the girl was on fenfluramine. This is in contrast to the finding in Dr. Dunleavy's patient. We cannot account for this. However, Dr. Dunleavy and his colleagues do not mention whether there was any weight change in their patient between the two studies. Growth hormone secretion may be diminished in the obese patient, returning to more normal levels with weight reduction.

The confusion in reports on the effect of fenfluramine on growth hormone levels ${ }^{23}$ may only reflect the many independent pathways regulating secretion. It seems possible that different tests of growth hormone secretion may test the integrity of different pathways. ${ }^{4} \mathrm{~A}$ drug acting on the central nervous system might stimulate some pathways and depress others, so that the recorded effect might depend on the particular test used. However, this would not explain the discrepancy between our result and that of Dr. Dunleavy and his colleagues. There is need for further study.

It remains questionable whether any change in growth hormone secretion in the patient on fenfluramine is of clinical importance. Growth hormone secretion and growth rate correlate only poorly. Without clinical evidence that fenfluramine does not depress growth rate-which may be diffcult to demonstrate-paediatricians may be slightly concerned that they are causing 
their obese patients to be not only slimmer, but shorter.-We are, etc.,

\section{E. M. E. Poskitt} P. H. W. RAYNER

Institute of Child Health,

Birmingham

1 Theodoridis, C. G., Brown, G. A., Chance, G. W., 2 and Rayner, P. H. W., Lancet 1969, 1, 1068. Rayner, P. H. W., South African
nal, 1971, 45, Suppl. (June) p. 28.

3 Brockie, B. K., Brown, P., Ahmed, N. E. L., Shirling, D., and Strong, J. A., South A frican Medical fournal, 1971, 45, Suppl. (June) p. 26.

4 Eastman, C. J, and Lazarus, L., Archives of Disease in Childhood. 1973, 48, 502 .

SIR,-Dr. D. L. F. Dunleavy and others (7 July, p. 48) have suggested that "in studying the mode of action of a drug such as fenfluramine it would seem important that the conditions of administration should resemble as nearly as possible those in which it is commonly used." By this they appear to mean that the effects of fenfluramine on growth hormone release are best studied in obesity.

Yet obesity may itself be associated with a diminished growth hormone response to exercise $^{1}$ or to hypoglycaemia. ${ }^{2}$ In nine of our own obese patients who had serial growth hormone studies an abnormally small growth hormone response returned to normal after the patients lost weight by dieting. The depressed growth hormone response thus appeared to be secondary to the obese state and sugigested a possible defect in hypothalamic control.

We submit that there may not be any real contradiction between the findings of Dr. Dunleavy and his colleagues and the findings of Mr. W. R. Sulaiman and Dr. R. H. Johnson (12 May, p. 329), since the latter authors were concerned with normal and acromegalic subjects. The situation in obesity is complex, and our own findings suggest that the effects of drugs should not be considered in isolation from any weight changes which these drugs may induce.We are, etc.,

M. H. LessoF

Department of Medicine,

Guy's Hospital Medical School,
London S.E.1

S. MCHARDY Young

Central Middlesex Hospital

London N.W.10

1 Roth, J., Glick, S. M., Yalow, R. S., and Berson, S. A., Metabolism, 1963, 12, 577.

2 Lessof, M. H., Mchlardy Young, S., and Greenwood, F. C., Guy's Hospital Reports, 1966, 115 ,

\section{Is Your Pain Really Necessary?}

SIR,-Previous comments under this title have not mentioned the possibility that spasdomic dysmenorthoea may involve an abnormal production of or sensitivity to the endometrial ("menstrual stimulant") prostaglandins which are known to cause the normal contractions of the menstruating uterus. ${ }^{1}$ A suggestion that the non-steroidal antiinflammatory drugs (which inhibit prostaglandin synthesis) might be of value in treating dysmenorrhoea has been made elsewhere; ${ }^{2}$ and it is now of interest that Dr. G. G. Hill (14 July, p. 106) may have successfully treated many cases with indomethacin, a drug of this kind.-I am, etc.,

V. R. PICKLES University College, Cardiff
1 Pickles, V. R., Hall, W. J., Best, F. A., and cology of the British Commonwealth, 1965, 2 Pickles, v. R., Nature, 1972, 239.33.

\section{Side Effects of the Pill}

SIR,-The letter from Drs. David $M$. and Susan M. Hall (14 July, p. 105) seems to suggest that loss of libido with oral contraceptives is psychological. They say that oral contraceptives are, like the menopause, a useful scapegoat on which to blame the worries of marriage and children.

If they had examined the full range of oral contraceptives originally tested by the Council for the Investigation of Fertility Control,' I am sure they would have been aware of the importance of the type of oral contraceptive in causing mood changes such as loss of libido, fatigue, anxiety, and depression. It would be most unlikely if lowdose-oestrogen oral contraceptives which can produce an atrophic endometrium and a dry vagina did not produce loss or decrease of libido in many women.

Before the endometrial growth becomes too scanty to be examined, the predominantly progestogenic low-oestrogen contraceptives now available produce endometrial glands which have high levels of monoamine oxidase for most of the month. In a normal cycle this enzyme is strong in the premenstrual phase only, which is when premenstrual tension may occur. We found a significant difference in the incidence of depression and loss of libido with the various types of oral contraceptives and this also corresponded with the endometrial monoamine oxidase activity. 1 The oestrogenic sequential regimens had a low incidence of depression and low monoamine oxidase activity.

As the Halls had 5 married women and 46 unmarried women in their group aged 20 or less it would seem unwise to come to conclusions about the effects of age and marriage from these figures. More significant, perhaps, is the fact that in their threemonth clinic survey they saw 170 women under 30 but only 27 women over 30 years old. This suggests that oral contraceptives are not well tolerated by older women.

Most women find oral contraceptives to be such an efficient and acceptable method of contraception that they usually discontinue only after trying several types and because of multiple side effects. In a followup of 341 women discontinuing the various types of pill, $40 \%$ noticed mood changes and $50 \%$ headaches. ${ }^{2}$ of 31 women stopping some of the low-oestrogen brands now available, I recently found that $70 \%$ noted depressive mood change.

It may be that women under 20 years old may be slower to have depressive changes and may be able to compensate for low oestrogen levels in some way, but it also seems possible that unmarried women are more reluctant to admit to side effects than married women. They want a method with virtually no risk of pregnancy and are less likely to have mature partners who are capable and willing to share responsibility for birth control.-I am, etc.,

New Malden,

Ellen C. G. Grant Nurrey

1 Grant. E. C. G., and Pryse-Davies, J., British Medical fournal, 1968, 3, 777.
4rant, E. C. G., British Medical foumal, 1969,
4, 73.
"Easy to Rise" Chair

SIR,-An opportunity has been taken to test and evaluate a new chair with several features of particular value to the aged and the disabled (see fig.).

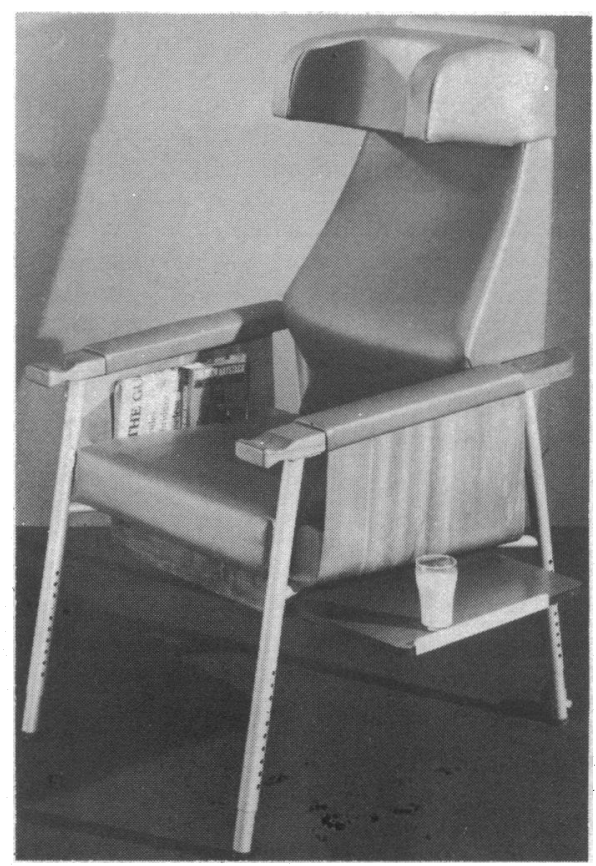

The height of the seat is adjustable between 17 and 24 in (43 and $61 \mathrm{~cm}$ ), with a specially shaped back, an extending sidetray, and large side-pockets for papers and other personal possessions etc. Both arms project forward, terminating with a grip fitting. Small wheels on the rear legs allow the chair to be tilted and moved when not occupied, and a headrest moulding can be adjusted to various heights. A detachable tray can be fitted over the arms.

The chair was tested both subjectively and objectively by 17 women and six men with a variety of disabilities, including gross hip and knee arthritis, extensive rheumatoid arthritis, Parkinson's disease, amputations, and hemiplegia. Their ages ranged from 39 to 85 years and the most common combination was obesity and hip arthritis. With two exceptions, the patients found the chair very comfortable or comfortable. The side slide tray and feeding table were satisfactory, and the headrest was appreciated for its ease of adjustment. The seat height was individually adjusted and with the extended arms was found helpful in assisting standing and sitting safely. A few minor criticisms were made by individual patients, and the manufacturers are considering whether small modifications can be made.

In conclusion, it justifies its name as the "Easy to Rise" chair, particularly for elderly patients with obesity and arthritis in the lower limbs.

I am grateful to Miss J. Sherwood, M.A.O.T., and members of the nursing staff who helped in this trial. The "Easy to Rise" Chair 100 is manufactured by Edward Doherty and Sons Ltd., Eedee House, Charlton Road, Edmonton, London N.9. -I am, etc.,

A. N. G. Clark

Geriatric Unit, Brighton General Hospital, Brighton 